\title{
Modelling operative and routine learning curves in manoeuvres in locks and in transit in the expanded Panama Canal
}

Luis Carral, ${ }^{1 *}$ Javier Tarrío-Saavedra, ${ }^{2}$ Adán Vega Sáenz, ${ }^{3}$ Johnny Bogle, ${ }^{4}$ Gabriel Alemán, ${ }^{5}$ and Salvador Naya ${ }^{2}$

${ }^{1}$ Research Group GEM, Universidade da Coruña, Higher Polytechnic University College, Campus de Esteiro, 15403 Ferrol, Spain.

${ }^{2}$ Research Group MODES, Research Center for Information and Communication Technologies (CITIC), Universidade da Coruña (UDC), Higher Polytechnic University College, Campus de Esteiro, 15403 Ferrol, Spain.

${ }^{3}$ Universidad Tecnológica de Panamá, Panamá.

${ }^{4}$ Universidad Marítima Internacional de Panamá, Panama City, Panamá.

${ }^{5}$ Unión de prácticos del Canal de Panamá, Panamá.

*Corresponding author. E-mail: lcarral@udc.es

Received: 10 March 2020; Accepted: 2 December 2020; First published online: 19 January 2021

Keywords: expanded Panama Canal, learning effect, learning curve, lockage time, transit time, non-linear regression, generalised additive models

\begin{abstract}
Piloting in the Panama Canal is exceptional as, due to its importance, the functions of the captains of vessels are taken over by pilots. Hence, prior to inauguration of the expanded canal, a limited number of pilots experienced on the existing canal were certified for the transit of Neopanamax vessels by means of planned and innovative individual learning. After this organisational training through operative training, with the implementation of the expanded canal in June 2016, the routine training started. Hence the learning curve in the performance of these manoeuvres will represent the growing skill acquired by both the pilots and the organisation. Given that the learning effect is measurable, this paper has the dual objective of determining two curve models: the organisation operative learning curve model and the routine learning curve model for pilots performing transit manoeuvres in the expanded Panama Canal waterways and the Cocolí and Agua Clara locks. Manoeuvre times in locks and transit in the whole of the canal were followed up continuously in the first 42 months of operation.
\end{abstract}

\section{Introduction}

In all cultures and languages there is a proverb which can be applied to any task in order to express that as the number of repetitions increases, experience leads to a reduction in the time and the effort required (Yelle, 1980; Dorroh et al., 1986; Lam et al., 2001; Mosheiov and Sidney, 2003; Jaber and Guiffrida, 2004; Carral et al., 2017, 2018a). This reduction in time comes from the performance of the activity in a more efficient way and is caused by the phenomenon known as learning effect, whose graphic representation is the learning curve.

Generally, the learning process is divided into two stages: the operative learning stage and the routine acquisition stage (Economic Commission for Europe, 1965; Thomas et al., 1986; Gottlieb and Haugbølle, 2010). It is during the former that learners acquire the basic skills and become familiar with the task. During the latter, they start to organise the operations so that an optimum performance will be achieved. 
For decades the personnel of the Panama Canal Authority (Autoridad del Canal de Panamá, ACP) - the organisation in charge of the transit of vessels (port pilots, tug boat captains, and lock operators) (Carral et al., 2017) - through their activities have developed efficient techniques in the performance of their functions in the existing canal (Carral et al., 2017, 2018a, 2018b, 2019a, 2019b). However, the different operations required in the expanded canal have determined specific learning needs for the personnel.

The concept of learning curve comes from the aeronautics industry and was first stated by T. P. Wright in 1936 (Wright, 1936). Subsequently, the applications of the learning effect reached other production sectors like shipbuilding (Argote and Epple, 1990), car industry (Baloff, 1971), chemical industry (Lieberman, 1984), photovoltaic production (Nemet, 2006) and semiconductors (Cook, 1991; Gruber, 1992, 1994, 1996, 1998; Chung, 2001). The direct application of the basic learning concept to strategic management has occurred more recently, from the early 1970s, as a result of its application by the Boston Consulting Group (Conley, 1970; Henderson, 1973), All the mentioned sectors coincide in production based on the performance of more or less broad series, in order to, as Jordan Srour et al. (2016) state, 'understand the dynamics of the learning effect by means of using the learning curve to favor the planning of the activities'.

In the case of other sectors of activity with production processes of differentiated units, the production activity will be made up of unit processes which can be considered as repetitive activities. This allows the learning curve concept to be adapted to their execution processes. A highly studied case of interest is that of operations and processes in civil construction, which allows the learning effect to be applied not only to diverse specific productive activities (Hinze and Olbina, 2009; Jarkas, 2010; Jarkas and Horner, 2011; Panas and Pantouvakis, 2014; Jordan Srour et al., 2016), but also to the different stages in civil construction projects like: design (Hamade et al., 2009), tenders (Wong et al., 2007), planning (Zhang et al., 2014) and even claims management (Lam et al., 2001; Hinze and Olbina, 2009).

In maritime navigation, within the transport activity, goods are not produced, but a service is provided. The management of a vessel during navigation is an activity totally different from those of the aforementioned sectors as there are multiple procedures, all of them valid for its development, with the final result of each navigated mile being different and unrepeatable. However, the situation of transit through a toll canal, like the Panama Canal, is not so different from a production activity, from a unit made up of repetitive processes (Carral et al., 2020), in this case: navigation along sea routes, manoeuvres in locks, and transit in el Corte Culebra and Lago Gatún (Carral et al., 2017; Carral et al., 2019a). Considering this, the effect of the learning curve might be applicable to the group of steering and transit activities in the extended Panama Canal.

Learning curves can be applied to both individuals and organisations (Lefcovich, 2003). Individual learning must be considered linked to the improvement obtained when individuals repeat a process and acquire skill, efficiency or practicality from their own experience. At the same time we can consider organisation learning as the result of practice, but coming from changes in the administration, the equipment, and the design of products and processes.

Lefcovich (2003) indicates that in the case of a company's employees both types of learning occur at the same time, and that very often the combined effect is described in a single learning curve. When considering the process of vessel transit through the extended Panama Canal, individual learning refers to the skill, efficiency or practice acquired, from their own experience, by pilots as the individuals responsible for the performance of the operation, while organisation learning results from the experience of a group of people working in the Maritime Traffic Control Center (MTCC), the Hydrology Department, tug boats, and locks (Carral et al., 2019a) (Figure 1). In the time representation of the transit time through the canal, the pilots' learning curve and the organisation learning curve are united, so that a single curve will describe the combined effect as superposition of both.

In spite of the importance and relevance of the learning effect on this type of activities with production processes of a differentiated unit, the literature that deals with this topic is still limited (Thomas, 2009; Malyusz and Pem, 2014), without consensus as to a model which will provide a good adjustment of historical data and, at the same time, offer acceptable predictive capacity (Jordan Srour et al., 2016). 


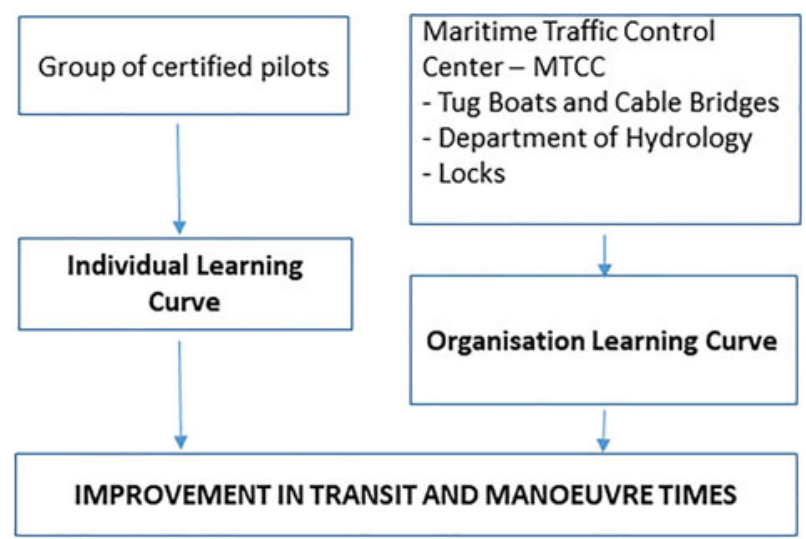

Figure 1. Routine learning related to transit time and manoeuvring of Neopanamax vessels in the expanded Panama Canal.

\section{Main objectives and contributions of the paper}

In the structure of this paper, first, information is supplied about precedents in the research on learning curves related to the production process, followed by a brief revision of the piloting process in the Panama Canal. After that, the research methodology is presented together with the simulation tool, and the results of the implementation of the concepts developed in the study of piloting in the extended Panama Canal are discussed.

The objectives of this paper, and, consequently, its main contributions, are the following:

(1) Analysis of the qualification process, both special and routine, of pilots.

(2) Determination of operative learning curves, prior to the implementation of the extended Panama Canal, and routine learning curves, after three and a half years of operations.

\section{Piloting regime}

When the Panama Canal commenced operation in the year 1914, a combined control system was implemented in which the port pilot assumed total control of the vessel during its way through the locks, and the captain was responsible for navigation along the canals under the former's counsel. This way of operating changed when, in 1953, the American management decided that piloting through the canal would be different from other navigation waterways: the canal port pilots would no longer act as counsellors but would assume total control of movements and navigation of vessels in transit, replacing the captain in these functions. Under these circumstances, Rodriguez (2011) states that traffic in the Panama Canal is managed and controlled in a very particular and different way from the rest of the world's waterways.

This unique piloting concept, apart from being critical to guarantee the efficacy and safety of the canal and the vessels crossing it, is key both to guarantee the control and execution of the schedule of transits, and to protect the integrity of the facilities of the canal before the vessels in transit.

With the development of other alternatives of logistical transport through the Isthmus of Panama, terminal ports were built at the ends of the canal. With this, port services added to the complex transit operations of the canal within the port pilots' responsibilities. This fact, together with the aforementioned unique piloting concept, has meant that, unlike conventional VTS (vessel traffic service) systems (Hughes, 2009; Ulusçu et al., 2009), traffic control services are managed in the Panama Canal through the MTCC (Rodriguez, 2011).

The MTCC is in charge of the generation of the schedule and resources assigned to each vessel for its transit, the schedule of the port pilots who will manage the vessel, and the follow-up of compliance 
with the schedule and of the availability of resources, so that transits will be performed safely and efficiently. These functions of scheduling, coordination and information provision mean that the canal operations follow instructions and guidelines on timetables and resources provided by the MTCC's traffic controllers.

As part of the VTS system of the Panama Canal, there are two port authorities, one at each end of the canal, working 24 hours a day, seven days a week, which are in charge of watching and ensuring the correct development of operations in the canal, and of dealing with any incident or emergency that may occur related to the vessels in transit, by coordinating the necessary actions and resources.

Traffic through the canal is organised in two different ways: by order of arrival of vessels, but taking into account the restrictions imposed on the vessel based on size, load and load hazards (Carral et al., 2019a); and by a booking system through which vessels can purchase a booking so as to transit on a specific date, and through which the ACP is committed to performing the transit on that date, within 18 hours after its start (ACP, 2006a).

The extension of the Panama Canal has determined the maintenance of the management and operation processes described above, but with the subsequent reinforcement of the existing structures so as to undertake a higher number of transits. Consequently, the MTCC was reinforced in 2012.

In comparison with the configuration of the Panama Canal from 1914 (Mc Cullough, 1977), the part of the canal known as the extended Panama Canal (EPC) (ACP, 2006a) is made up of the access waterways and the locks complex corresponding to Cocolí and Agua Clara (Carral et al., 2016) (Table 1). Unlike the locks of the 1914 configuration, the new locks have dimensions appropriate to manoeuvre 'neo-panamax' vessels of between 150,000 and 170,000 displacement tons (ACP, 2006b). The locks work with rolling gates and gravity filling and purge systems through inner conduits and openings on the lateral walls of the lock chambers (Carral et al., 2017). Tug boats are used to position and manoeuvre vessels inside the lock chambers (Carral et al., 2017).

\section{Certification process of pilots for the EPC - operative learning.}

The ACP recruits its pilots and tug boat captains mainly from Panamanian navigation officers, and trains them through programmes with an average duration of two years. Once the certification has been obtained, in the specific case of operation pilots, these progress from level 1 to level 9 over approximately nine years, eventually becoming qualified pilots able to transit any vessel through the existing canal (Table 2). In order to become pilots certified to perform in the EPC, a double four-year process is required (levels 9, 10 and 11) (Table 2).

\subsection{Routine certification of pilots}

The training to obtain the certification for pilots is completely carried out in the facilities of the canal, mainly through the Simulation and Maritime Development Center (SIDMAR) and the Scale Maneuver Certification Center (SMCC). SIDMAR has been certified by the Panama Maritime Authority under the programmes of the International Convention on Standards of Training, Certification and Watchkeeping for Seafarers, 1978 (Figure 2).

SMCC opened a few months prior to the opening of the EPC in 2016. This facility, which complements the Simulation Certificate received at the SIDMAR, is in charge of the training on scale vessel manoeuvres. The new SMCC comprises $15 \cdot 5$ hectares and has two lakes (North and South) connected by a canal of $518 \mathrm{~m}$ after the Gaillard Cut design. In the North lake there is an area of deep water which is similar to the approach to the Atlantic breakwater. The new SMCC also has berths, replicas of both the new and the existing locks, gates and chambers, all of them at 1:25 scale. It is equipped with carefully built scale models of canal tug boats and vessels, including a bulk carrier modelled on the Nord Delphinus, and a container ship modelled on the Maersk Edinburgh. Additionally, there is a liquefied natural gas tanker, the Stream $L N G$.

Figure 2 shows the routine certification process of pilots for operations in the EPC. 
Table 1. Main components of the previous and expanded Panama Canal; locks, navigation channels, anchorages and lakes.

\begin{tabular}{|c|c|c|c|c|c|c|c|c|c|}
\hline \multirow{2}{*}{$\begin{array}{l}\text { Section } \\
\text { Lock }\end{array}$} & \multicolumn{3}{|c|}{ Common to both } & \multicolumn{4}{|c|}{ Previous canal } & \multicolumn{2}{|c|}{ Expanded canal } \\
\hline & & & & & Gatún & $\begin{array}{l}\text { Pedro } \\
\quad \text { Miguel }\end{array}$ & Miraflores & Cocolí & $\begin{array}{l}\text { Agua } \\
\text { Clara }\end{array}$ \\
\hline $\begin{array}{l}\text { Navigation } \\
\text { channel } \\
(72 \mathrm{~km})\end{array}$ & $\begin{array}{l}\text { Pacific } \\
\text { Ocean } \\
\text { channel }\end{array}$ & $\begin{array}{c}\text { Gatún Lake } \\
\text { channel }\end{array}$ & $\begin{array}{c}\text { Culebra Cut } \\
\text { channel }\end{array}$ & $\begin{array}{c}\text { Atlantic } \\
\text { Ocean } \\
\text { channel }\end{array}$ & & & & & \\
\hline Lake & & & & & & Miraflores & & & \\
\hline Distance $(\mathrm{km})$ & $1 \cdot 3$ & $45 \cdot 8$ & $12 \cdot 7$ & $3 \cdot 2$ & & & & $5 \cdot 8$ & $3 \cdot 2$ \\
\hline
\end{tabular}

Note: author's own data based on Carral et al. (2018). 


\begin{tabular}{|c|c|c|c|c|c|}
\hline $\begin{array}{l}\text { Type of vessel (length } \\
\text { and displacement) }\end{array}$ & Max. vessel beam & Category & $\begin{array}{l}\text { Time spent on the } \\
\text { grade (weeks) }\end{array}$ & $\begin{array}{l}\text { Number of } \\
\text { transits required }\end{array}$ & Denomination \\
\hline Minor vessels & - & FE-5 & $104-156$ & 60 & Pilot in Preparation \\
\hline Up to $225 \mathrm{ft}$ and $12,000 \mathrm{~T}$ & - & CP-02 & 34 & 70 & Pilot in Training \\
\hline Up to $526 \mathrm{ft}$ and $20,000 \mathrm{~T}$ & - & CP-03 & 54 & 130 & Pilot in Operation \\
\hline Up to $600 \mathrm{ft}$ and $12,000 \mathrm{~T}$ & - & CP-04-01 & 26 & 30 & \\
\hline Up to $600 \mathrm{ft}$ and $25,000 \mathrm{~T}$ & - & CP-04-02 & 26 & 30 & \\
\hline \multirow[t]{3}{*}{ Up to $899.9 \mathrm{ft}$} & - & CP-04-03 & 52 & 60 & \\
\hline & - & CP-04-04 & 52 & 60 & \\
\hline & - & CP-04-05 & 52 & 60 & \\
\hline \multirow[t]{2}{*}{ Up to $900 \mathrm{ft}$} & - & CP-04-06 & 52 & 60 & \\
\hline & - & CP-04-07 & 52 & 60 & \\
\hline \multirow[t]{2}{*}{ Up to $966.99 \mathrm{ft}$-Panamax-Extra } & - & CP-04-08 & 52 & 200 & \\
\hline & - & CP-04-09 & 104 & 120 & Higher Pilot 1 \\
\hline Neopanamax & 135 & CP-04-10 & 104 & 120 & Higher Pilot 2 \\
\hline Neopanamax B & Greater than 135 & CP-04-11 & - & 120 & Higher Pilot 3 \\
\hline
\end{tabular}


Table 3. Space-activity relationship, in relation to the learning curves and their application with the degree of influence on transit time.

\begin{tabular}{|c|c|c|c|}
\hline Space-activity & Applicable learning curve & $\begin{array}{l}\text { Degree of } \\
\text { influence on } \\
\text { transit time }\end{array}$ & $\begin{array}{l}\text { Applicable } \\
\text { bibliographi- } \\
\text { cal reference }\end{array}$ \\
\hline $\begin{array}{l}\text { Sea channels } \\
\text { (Pacific and } \\
\text { Atlantic) }\end{array}$ & $\begin{array}{l}\text { - Pilots' individual learning } \\
\text { - Organisation's learning } \\
\text { - MTCC }\end{array}$ & Low & (Carral et al., 2019a) \\
\hline $\begin{array}{l}\text { Locks (Cocolí } \\
\text { and Aguas } \\
\text { Claras) }\end{array}$ & $\begin{array}{l}\text { - Pilots' individual learning } \\
\text { - Organisation's learning } \\
\text { - Tug boats } \\
\text { - Mooring and cable } \\
\text { personnel } \\
\text { - Dept. of Hydrology - locks }\end{array}$ & Very high & (Carral et al., 2017) \\
\hline $\begin{array}{l}\text { Navigable } \\
\text { waterways } \\
\text { (Coste Culebra } \\
\text { and Lago } \\
\text { Gatún) }\end{array}$ & $\begin{array}{l}\text { - Pilots' individual learning } \\
\text { - Organisation's learning } \\
\text { - Tug boats } \\
\text { - MTCC }\end{array}$ & High & (Carral et al., 2019a) \\
\hline
\end{tabular}

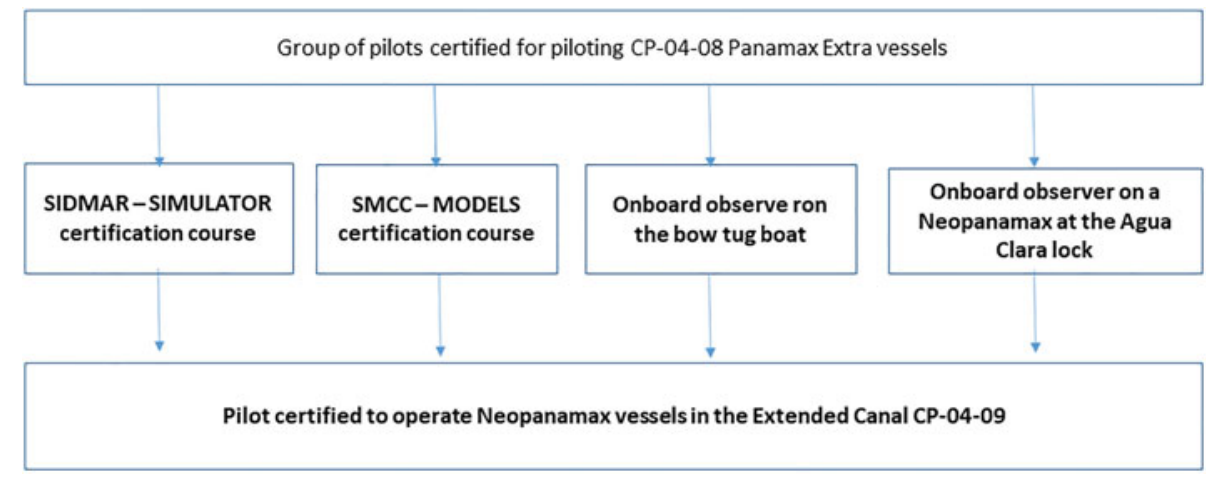

Figure 2. Sequence of routine certification for service in the expanded Panama Canal.

\subsection{Special certification for pilots}

Piloting in the EPC, due to its exceptional importance, required individual learning for a limited group of experienced pilots prior to the opening of the EPC. As a complement to the personal training, an operative learning programme was developed, and implemented on dates right after the opening, which used the bulk carrier Baroque for the training of the organisation as well as a new group of pilots who were fully certified for the existing canal (Figure 3).

After initial training at SIDMAR, the final stage of the special certification consisted of the performance of 36 daily transits in the Agua Clara lock (the entrance from the Atlantic Ocean to Lake Gatún and vice versa) with the presence onboard of a certified pilot and four trainee pilots. Thus, in a period slightly longer than a month, a group of more than 100 pilots was certified for the EPC (Figures 3 and 4).

Since then, the routine learning stage has been developed in the pilots' work, whose manifestation is presented in the evolution of the times taken to perform manoeuvres in the Cocolí and Agua Clara locks and transits in the navigation channels (Table 4). 


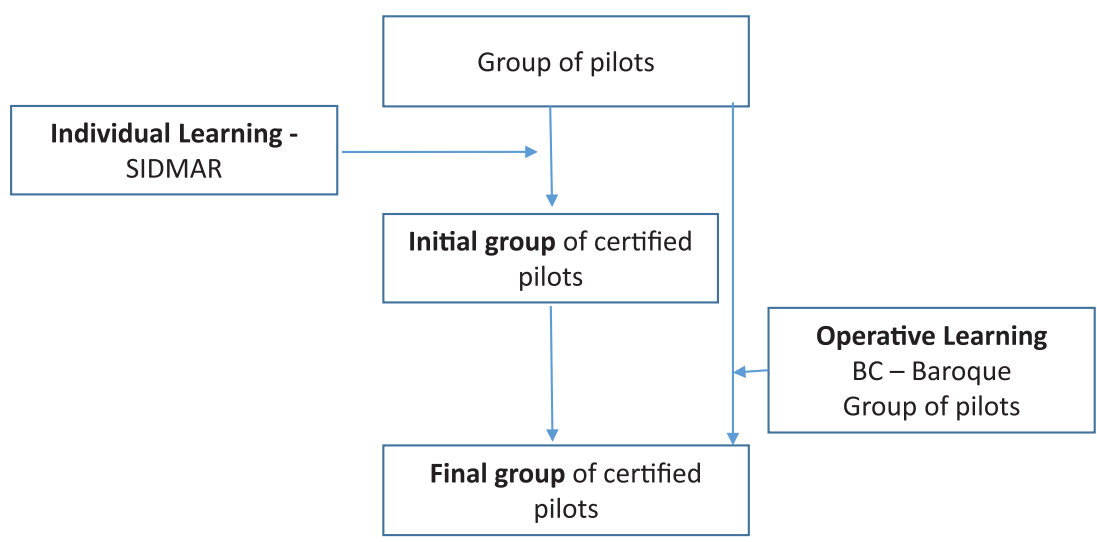

Figure 3. Certification programme for pilots operating in the expanded Panama Canal - operative learning vessels.

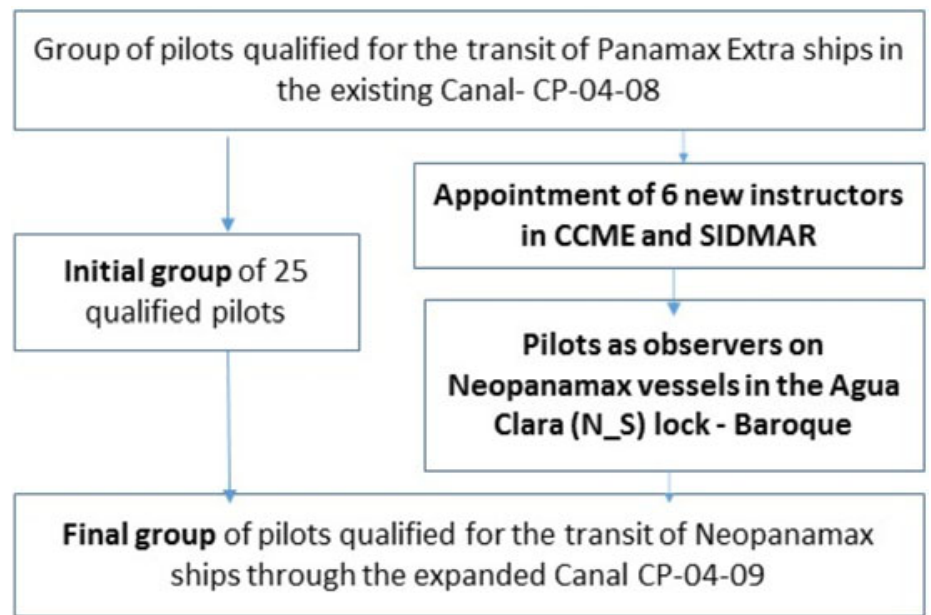

Figure 4. Sequence of special certification for services in the expanded Panama Canal. Use of Neopanamax vessel, the bulk carrier Baroque.

\section{Estimation of learning curves corresponding to the EPC locks}

\subsection{Learning curve for installation and pilot training using the Baroque}

The use of the bulk carrier Baroque for pilot and installation training is mentioned in the previous section. This vessel was used by different pilots and personnel, and guided across the same lock, namely Agua Clara. A total of 44 transits were performed from 25 July to 5 August 2016. This specific case study was performed over a short period of time, 11 days. Therefore, it was expected that climate (which can influence the time in transit through the locks) would experience only small variations. In addition, other variables potentially influencing time in transit, such as lock, type of vessel, and vessel size, were also maintained as constant. This fact makes this experiment ideal to measure and estimate the learning effect on vessel time in transit through the locks of the EPC.

The progression of the study revealed an improvement in pilotage over time. Figure 5 shows time in transit of Baroque through the lock with respect to the time (measured in days) elapsed from the beginning of the training activities on 25 July 2016.

Figure 5 shows that, although there was high variability of time in transit on each day of the study, a non-linear asymptotic decreasing trend can be observed. As time passes, the time in transit of the vessel 
Table 4. Asymptotic fitting model parameters with $95 \%$ confidence interval (CI) and the corresponding $P$-values using the $t$ test.

\begin{tabular}{llcr}
\hline & \multicolumn{3}{c}{ Dependent variable } \\
\cline { 2 - 4 } Parameters & Estimates & CI & $P$-value \\
\hline \multirow{2}{*}{ Asym } & $179 \cdot 31$ & $169 \cdot 34-189.28$ & $<0 \cdot 001$ \\
$R_{0}$ & $269 \cdot 37$ & $234 \cdot 70-304.05$ & $<0 \cdot 001$ \\
lrc & -1.86 & $-2 \cdot 49$ to -1.23 & $<0 \cdot 001$ \\
\hline
\end{tabular}

Table 5. Position and dispersion measures of transit time for all combinations of the levels of type of vessel, lock and transit direction factors.

\begin{tabular}{lllccc}
\hline Lock & Direction & \multicolumn{1}{c}{ Type } & $\begin{array}{c}\text { Transit time } \\
\text { mean }(\mathrm{min})\end{array}$ & $\begin{array}{c}\text { Transit time st. } \\
\text { dev. (min) }\end{array}$ & $\begin{array}{c}\text { Transit time } \\
\text { median (min) }\end{array}$ \\
\hline Agua Clara & North & Container & $160 \cdot 0000$ & $34 \cdot 40689$ & $156 \cdot 5$ \\
Agua Clara & North & LNG & $127 \cdot 2667$ & $13 \cdot 66156$ & $130 \cdot 0$ \\
Agua Clara & North & LPG & $132 \cdot 6667$ & $32 \cdot 17030$ & $134 \cdot 0$ \\
Agua Clara & South & Container & $164 \cdot 1744$ & $31 \cdot 95261$ & $165 \cdot 0$ \\
Agua Clara & South & LNG & $133 \cdot 8696$ & $16 \cdot 57848$ & $133 \cdot 0$ \\
Agua Clara & South & LPG & $160 \cdot 5000$ & $38 \cdot 16275$ & $154 \cdot 0$ \\
Cocolí & North & Container & $165 \cdot 0941$ & $32 \cdot 07891$ & $161 \cdot 5$ \\
Cocolí & North & LNG & $141 \cdot 2000$ & $31 \cdot 65258$ & $133 \cdot 0$ \\
Cocolí & North & LPG & $146 \cdot 8947$ & $34 \cdot 80444$ & $147 \cdot 0$ \\
Cocolí & South & Container & $159 \cdot 6860$ & $32 \cdot 74510$ & $157 \cdot 0$ \\
Cocolí & South & LNG & $122 \cdot 9130$ & $24 \cdot 48546$ & $122 \cdot 0$ \\
Cocolí & South & LPG & $145 \cdot 6364$ & $39 \cdot 78085$ & $138 \cdot 0$ \\
\hline
\end{tabular}

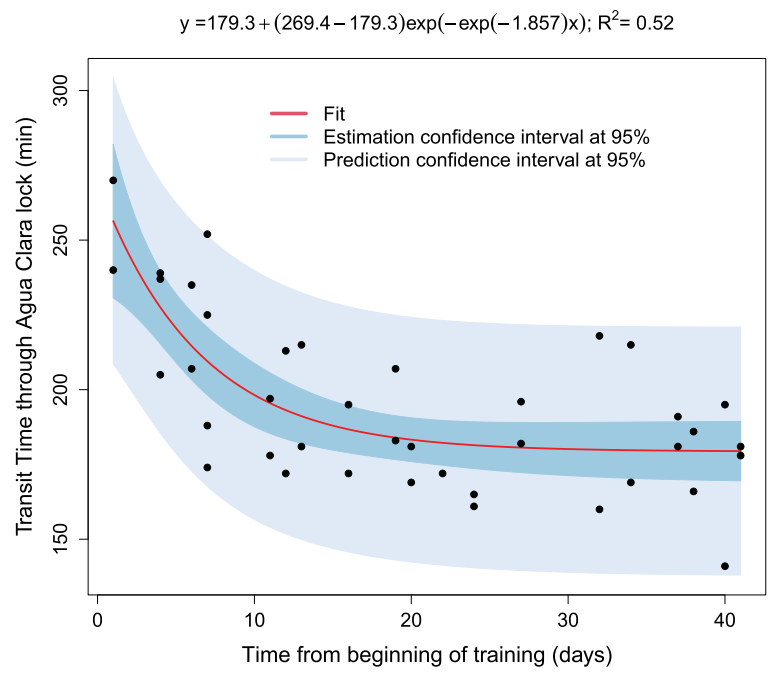

Figure 5. Scatterplot of Baroque vessel transit time versus time from the beginning of training. In addition, asymptotic non-linear fitting model is included with estimation and prediction $95 \%$ confidence intervals. The expression of the asymptotic fitting model and the corresponding determination coefficient are also shown. 
tends to decrease asymptotically. Figure 5 shows the fitting of a non-linear asymptotic model defined by Pinheiro and Bates (2000), Pinheiro et al. (2018) and Robles-Bykbaev et al. (2018):

$$
\text { Transit Time }=\text { Asym }+\left(R_{0}-\text { Asym }\right) \cdot \exp (-\exp (\operatorname{lrc}) \cdot \text { Time } \cdot \text { from the beginning }) .
$$

This expression is also defined by the following parameters:

- Asym: Final asymptote.

- $R_{0}$ : Initial value of the response variable (transit time).

- $l r c$ : Parameter connected with the rate of change of dependent variable (i.e., transit time), i.e., the natural logarithmic of the constant rate.

Table 4 shows that all the parameters (Estimate column) are statistically significant $(P$-value of $t$ test $=\operatorname{Pr}(>|\mathrm{t}|)<0.05$ for all the cases $)$. In addition, the determination coefficient is $R^{2}=0.52$, i.e., the effect of learning explains more than $50 \%$ of all the variability of time in transit through the locks. In fact, the estimated expected time in transit decreases $90 \mathrm{~min}$, from $R_{0}=269.4 \mathrm{~min}$ to Asym $=179.3 \mathrm{~min}$. The time in transit decreases in an exponential way until reaching an asymptote at $179 \cdot 3 \mathrm{~min}$. This trend can be explained by the fact that, at the beginning, implemented changes and learning significantly decrease the time in transit. The rate of change of the transit time then continuously decreases because the room for improvement of the canal organisation also decreases over time until reaching a saturation limit of about $179 \mathrm{~min}$. Therefore, the actions of the APC in order to improve the services provided for dealing with vessel transit are successful, decreasing the transit time by more than $30 \%$. If the APC wished to go significantly beyond this limit, structural, technological or logistical changes should be implemented. Estimation and prediction intervals have been also included in Figure 5. The confidence interval is used to answer the following question: what is the mean transit time of the vessels given a particular time from the beginning of training? The prediction interval tries to answer this other question: what is the transit time at the time $x$ from the beginning of training? Intervals provide an answer by estimating a range of values that contain the true population parameter with reasonable confidence level (often 95\%) (Bates and Watts, 2007).

\subsection{Estimation of learning curves corresponding to real operation time}

In this section, the time in transit through the Cocolí and Agua Clara locks will be modelled with respect to the time passed since the inauguration of the EPC. We want to know if the learning effect observed in training on the Baroque vessel is also reproduced in EPC operating conditions. We also intend to obtain information about the trend of the learning curve, which accurately characterises the canal organisation performance.

\subsection{Exploratory analysis: descriptive statistics}

Before the fitting of parametric regression models that allow us to estimate the learning curves of the Panama Canal organisation (specifically that corresponding to the expanded locks of EPC), the application of statistical exploratory analysis is needed. Indeed, before modelling, we intend to identify the variables that really affect the values of time in transit through the locks of the EPC. Thus, the application of techniques such as graphical analysis of variance (ANOVA) is necessary (Box, 2011). Consequently, Figure 6 accounts for the relation of dependence between, on the one hand, the time in transit response variable and, on the other hand, the factors of vessel direction (North or South), the lock (Cocolí and Agua Clara) and vessel type (liquid natural gas, LPG and container, the three main types of vessels that use the Panama Canal). The notched boxplots (including a confidence interval for the median) show that there are differences in the median and dispersion of transit time depending on the values of type, lock and direction of vessel. In fact, the transit time shows the Time Containers $>$ Time $_{\mathrm{LPG}}>$ Time $_{\mathrm{LNG}}$ trend in all the combinations of factor levels. In order to complete the information of Figure 6 , a 


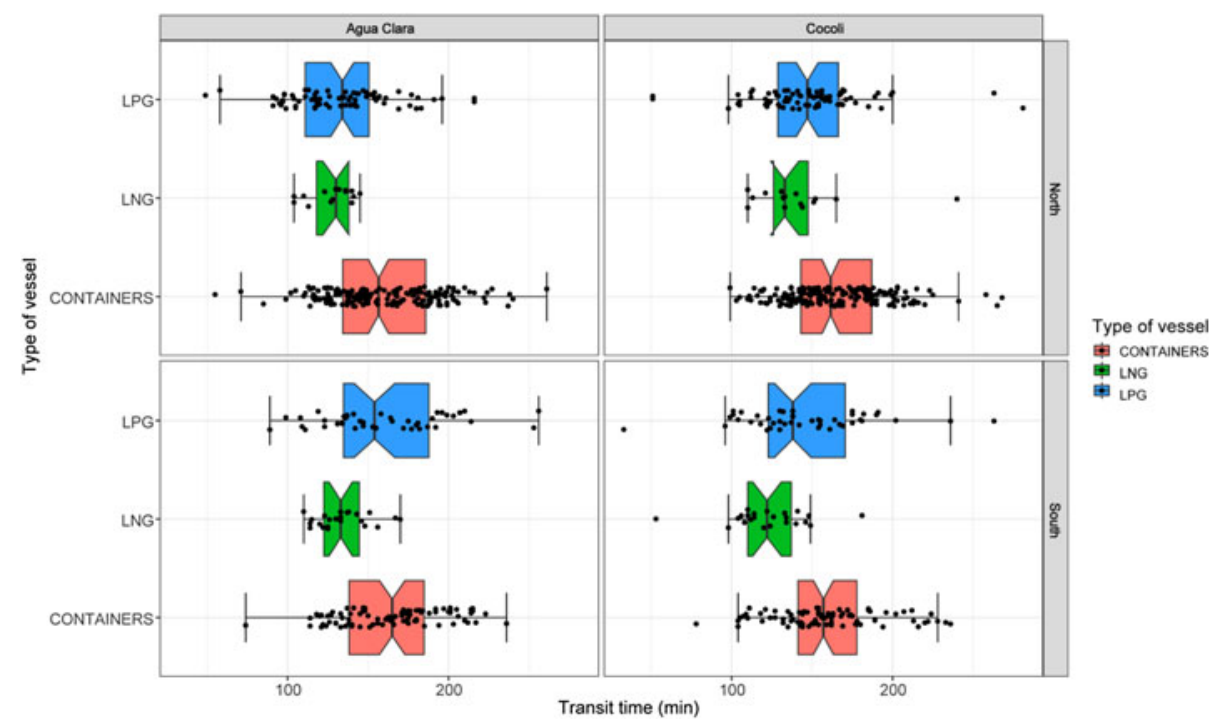

Figure 6. Notched boxplots for the transit time depending on the combination of the levels of type of vessel, lock and transit direction.

Table 6. Linear and smooth effects of GAM fitting model to explain the vessel transit time through locks. Confidence interval (CI) of 95\% for the model parameters and smooth effect (of time of experience), the corresponding $P$-values, and the determination coefficient are also included.

\begin{tabular}{|c|c|c|c|}
\hline \multirow[b]{2}{*}{ Predictors } & \multicolumn{3}{|c|}{ Transit time } \\
\hline & Estimates & $\mathrm{CI}$ & $P$-value \\
\hline (Intercept) & $77 \cdot 83$ & $50 \cdot 84$ to $104 \cdot 81$ & $<0.001$ \\
\hline Beam & $0 \cdot 54$ & 0.36 to 0.73 & $<0 \cdot 001$ \\
\hline Type of vessel [LNG] & $-27 \cdot 62$ & $-34 \cdot 21$ to $-21 \cdot 04$ & $<0.001$ \\
\hline Type of vessel [LPG] & $-2 \cdot 86$ & $-9 \cdot 40$ to 3.67 & $0 \cdot 390$ \\
\hline Direction [South] & 8.69 & $3 \cdot 06$ to $14 \cdot 31$ & 0.003 \\
\hline Lock [Cocolí] & $8 \cdot 29$ & 3.50 to 13.08 & 0.001 \\
\hline Direction [South] * lock [Cocolí] & $-16 \cdot 56$ & $-24 \cdot 42$ to $-8 \cdot 70$ & $<0 \cdot 001$ \\
\hline Smooth term (time) & $2 \cdot 77$ & & $<0.001$ \\
\hline$R^{2}$ & \multicolumn{3}{|c|}{$0 \cdot 381$} \\
\hline
\end{tabular}

statistical summary of position and dispersion measures of the transit time for each combination of the lock, direction and type of vessel factors is shown in Table 6. Thus, we can observe differences in the transit time depending on the lock, the direction and the interaction between direction and lock. Namely, the longest transit times correspond to the combination of, on the one hand, Agua Clara lock and South direction or, on the other hand, Cocolí lock and North direction. In other words, it seems that vessels tend to take longer to pass through the locks when they come directly from the sea. The assignable causes of this trend are the more numerous and complex manoeuvres required to pass from the ocean into the Panama Canal. The main effects of lock and direction factors over the transit time are not as clear as in the case of type of vessel because they overlap with the effect of their iteration.

Considering the information provided by Table 6 and Figure 6, the transit time depends on the vessel type, direction and lock factors. Thus, we should take into account the values of these factors 
when modelling the time in transit through the locks, and specifically the learning curves of the canal organisation and personnel.

\subsection{Exploratory analysis: Generalised additive models application}

Once a descriptive analysis of the dataset has been performed, the second step for the modelling of the learning curves is to estimate the type and magnitude of the effects of time, vessel type, and lock and vessel direction on the transit time. This task can be performed by the estimation of generalised additive models (GAM) (Wood, 2017; Robles-Bykbaev et al., 2018). These are multivariate models that allow us to include both linear and smooth (fitted by nonparametric methods such as b-splines) effects of the predictors (Wood, 2017). Initially, the effect of experience time on the transit time of ships through the new locks is not known, neither the type nor the magnitude. Thus, the application of GAM makes it possible to estimate the type (linear or non-linear) and magnitude of the effect of experience time, apart from the effect of the other qualitative factors, namely type of ship, lock and direction.

The combinations of the levels of these factors define scenarios where the learning curve can be different, thus the influence of the levels of these factors and their interactions on the time in transit should be checked by regression modelling. In addition, it is also interesting to measure the effect of vessel size on the time in transit through the locks. Although the objective of this work is to identify, describe and model the relationship between the time in transit and the date (learning curve), characterising and measuring the effect of vessel size on the time in transit can also provide interesting information about the performance of the Panama Canal. In this regard, Figure 7 shows that the variable Type of Vessel is strongly related to the vessel dimensions. In fact, we can observe well-defined clusters corresponding to the type of vessel from the value of vessel length overall (LOA). The relation between beam and type of vessel is less important, that is, it is more difficult to separate the different types of vessels attending to their beam values. Therefore, in order to measure the effect of vessel size, we will introduce in the GAM (as $X s$ variables) the type of vessel factor in addition to the vessel beam quantitative predictor.

Assuming that the response, time in transit, is normally distributed, a GAM as a function of time of experience, beam, type of vessel, direction, lock and the iteration of lock and direction is estimated. The estimates of the model are shown in Table 4, whereas Figure 8 shows the main effects of the predictors and the effect of the iteration direction-lock.

Regarding the estimation of learning curves, the most important result shown in Figure 8 is that the effect of the time of experience on the vessel time in transit, the learning curve, is non-linear, specifically asymptotic type (Figure $8[a]$ ). Table 6 shows that this effect is statistically significant $(P$-value $<0 \cdot 01)$. This result justifies the application of parametric non-linear asymptotic regression models to estimate the learning curves. The asymptotic effect of the time of experience on the time in transit through locks means that, at the beginning, there was wide room for improvement and all the actions related to manoeuvres, logistics and pilots' learning, among others, that the APC had implemented had a rapid success. However, as time passed, there was a decrease in the rate at which the transit time decreased, until it reached a saturation zone. This asymptote could indicate that, with the available resources (environment, labour, financing, machinery, available facilities), the transit time through each lock cannot be significantly reduced, that is, the organisation has optimised the use of the new facilities to the maximum and has therefore reached a period of maturity. Reducing the transit time below the limits reached would entail changes in the resources and procedure employed.

Moreover, the fitted GAM provides estimates for the variables apart from learning effect. Namely, the South direction produces a significantly longer time in transit through the locks than in the corresponding North direction (Figure 8[d]), and the expected time in transit tends to be higher in the Cocolí lock compared with Agua Clara (Figure 8[e]). In addition, the expected time in transit of container vessels tends to be longer than that of LPG vessels, and the mean time in transit of LNG vessels tends to be shorter than that of LPG vessels (Figure 8[c]). Table 6 shows that the effects of direction, type of vessel and lock on the time in transit through the locks are statistically significant (all the $P$-values equal to or lower than $0 \cdot 01$, excepting that corresponding to the effect of LNG vessels compared with container 


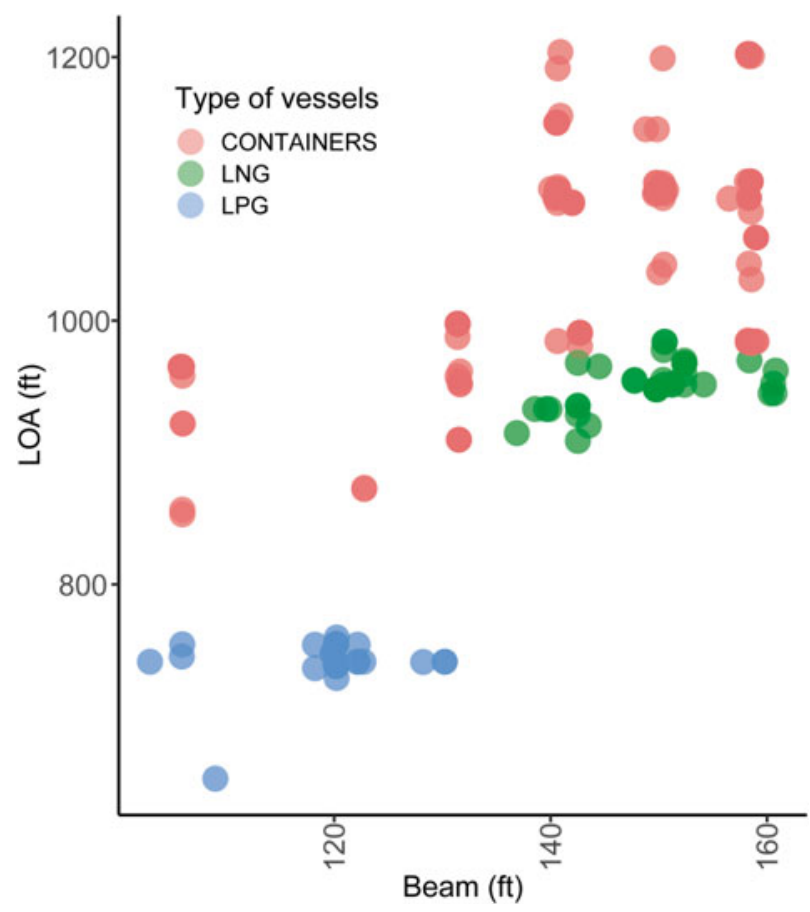

Figure 7. Scatterplot of the LOA as a function of the beam of each vessel. Each point corresponds to a vessel passing through one of the locks. The colour of each point corresponds to the type of vessel.

vessels). Specifically, the GAM estimates that LPG vessels take almost 3 min (in mean values) less to pass through the locks than container vessels, and this difference increases to 28 min for LNG vessels. Although the LNG and LPG vessels are very similar, the LNG ones have priority in the traffic on the canal on account of their cargo, hence they tend to pass faster. Moreover, the expected value of a vessel's transit time will be 8.69 min higher if the direction is South, and 8.29 min higher if the lock is Cocolí. In this regard, the effect of the tide in the Pacific may be one of the causes (in the Caribbean the variation in sea level is of a lesser magnitude). Another important result of the model is that the effect of iteration between direction and lock factors on the time in transit is significant ( $P$-value $<0.001$ in Table 6). In other words, the transit time through the locks is significantly longer if the transit is made from the sea. Indeed, Figure 8(f) shows the time in transit is higher for the combination of Cocolí lock and North direction, and Agua Clara lock with South direction. Considering the effect of the interaction shown in Figure 8(f), crossing the locks by entering directly from the sea entails a transit time of between $7 \cdot 5$ and 10 min longer. Finally, the effect of vessel beam on the time in transit is linear and increasing. Namely, when the beam increases by $1 \mathrm{ft}$, the time in transit through the locks tends to increase by $0.54 \mathrm{~min}$.

It is important to note that the fitted model, as a function of time of experience, beam, vessel type, direction and lock, explains $38.1 \%$ of the variability of the transit time through the locks. The unexplained variability of transit time could be related to other variables such as those corresponding to the weather, and manpower, among many others.

\subsection{Parametric modelling of learning curves}

In the previous section, the underlying non-linear model that relates the time in transit with respect to the experience time of the EPC personnel and organisation was identified. The next step is to fit this parametric asymptotic model to estimate the learning curves. Assuming that the time in transit depends on the type of vessel, direction, lock and the interaction between direction and lock, the 
(a)

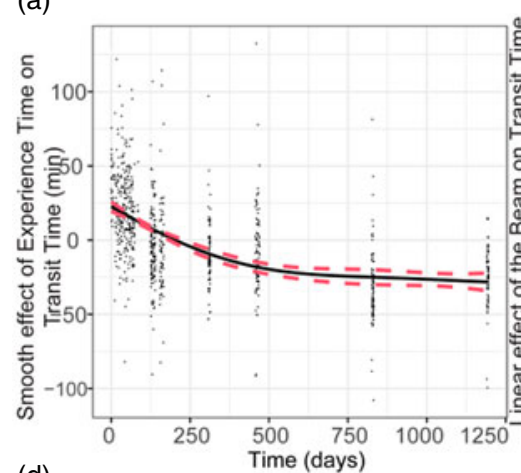

(d)

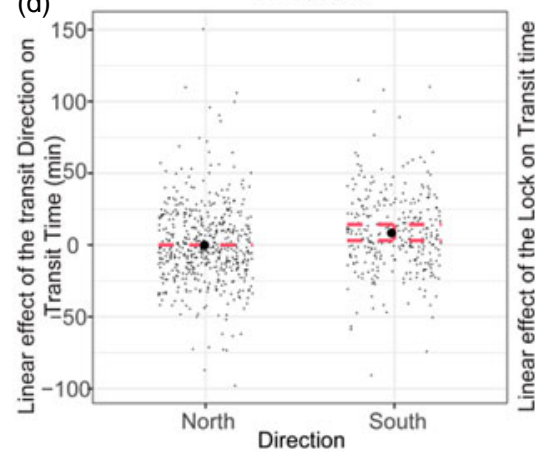

(b)

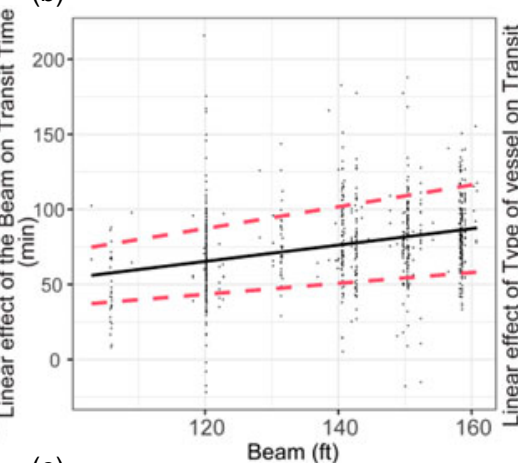

(e)

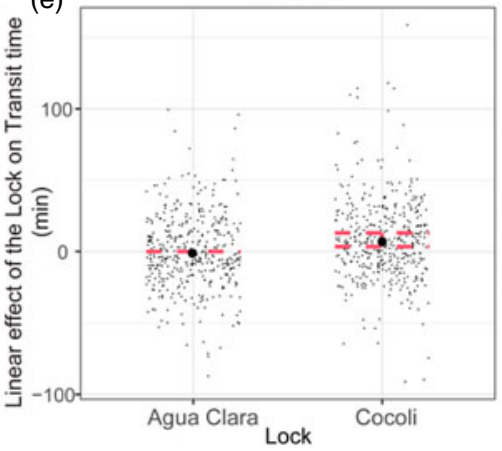

(c)

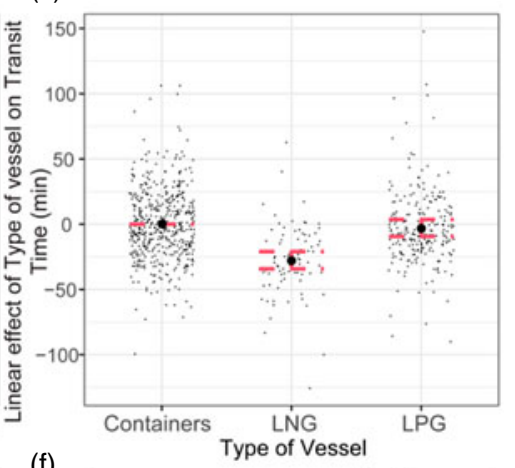

(f)

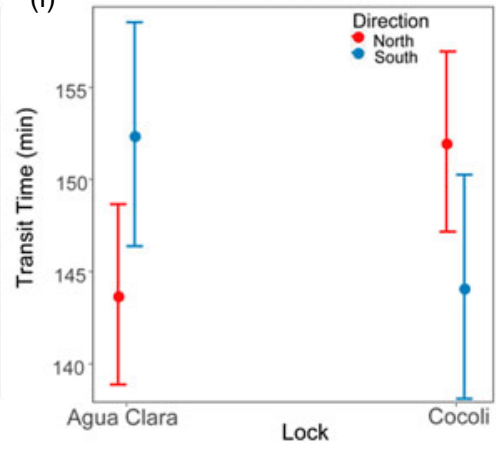

Figure 8. Linear and smooth effects on time in transit estimated by GAM fitting model with 95\% confidence intervals. (a) Learning effect or effect of time of experience. (b) Linear effect of the vessel beam on the transit time through locks. (c) Effects of the levels of type of vessel, with container vessels as reference. (d) Effects of the levels of transit direction, with North as reference. (e) Effect of the lock factor, with Agua Clara as reference. (f) Effect on time in transit of the interaction between direction and lock.

asymptotic model will be fitted separately for each combination of factors. As a result, we will obtain a different model expression for each combination of factor levels. In all the cases, an initial solution for the model parameters is obtained by the application of evolutionary global optimisation algorithms such as differential evolution (Ríos-Fachal et al., 2014; Janeiro-Arocas et al., 2016; Tarrío-Saavedra et al., 2017). From this initial solution, the non-linear asymptotic model is fitted using Newton Raphson and Levenberg-Marquardt optimisation algorithms (Janeiro-Arocas et al., 2016). R software has been used to perform this task, as in the case of the exploratory analysis, specifically, the nls2, nlme, mgcv, robustbase and DEoptim packages (Mullen et al., 2011; Grothendieck, 2013; Wood, 2017; Pinheiro et al., 2018; Maechler et al., 2019). The scatterplots and the result of the fitting of the asymptotic non-linear regression model to the studied four scenarios (Cocolí lock - North direction, Cocolí lock South direction, Agua Clara lock - North direction and Agua Clara lock - South direction) are shown in Figure 9. Real data and the estimated confidence intervals for the conditioned mean and prediction intervals for the response variable are included at a confidence level of $95 \%$. Each column corresponds to a different scenario. Namely, the Figure 9(a)-9(c) panels account for the asymptotic model fitted to the real data corresponding to container, LNG and LPG vessels, respectively, in the Cocolí lock with North direction. The Figure 9(d)-9(f) panels show the scatterplots and the fittings of time in transit depending on the time of experience in operating the EPC for the container, LNG and LPG vessels, respectively, in the Cocolí lock - South direction scenario. Figure 9(g)-9(i) panels account for the transit time versus time of experience and asymptotic model fittings of container, LNG and LPG vessels in the Agua Clara lock - North direction scenario, whereas the Figure 9(g)-9(i) panels show the fittings for container, LNG and LPG vessels in the Agua Clara lock - South direction scenario. Moreover, the expression 

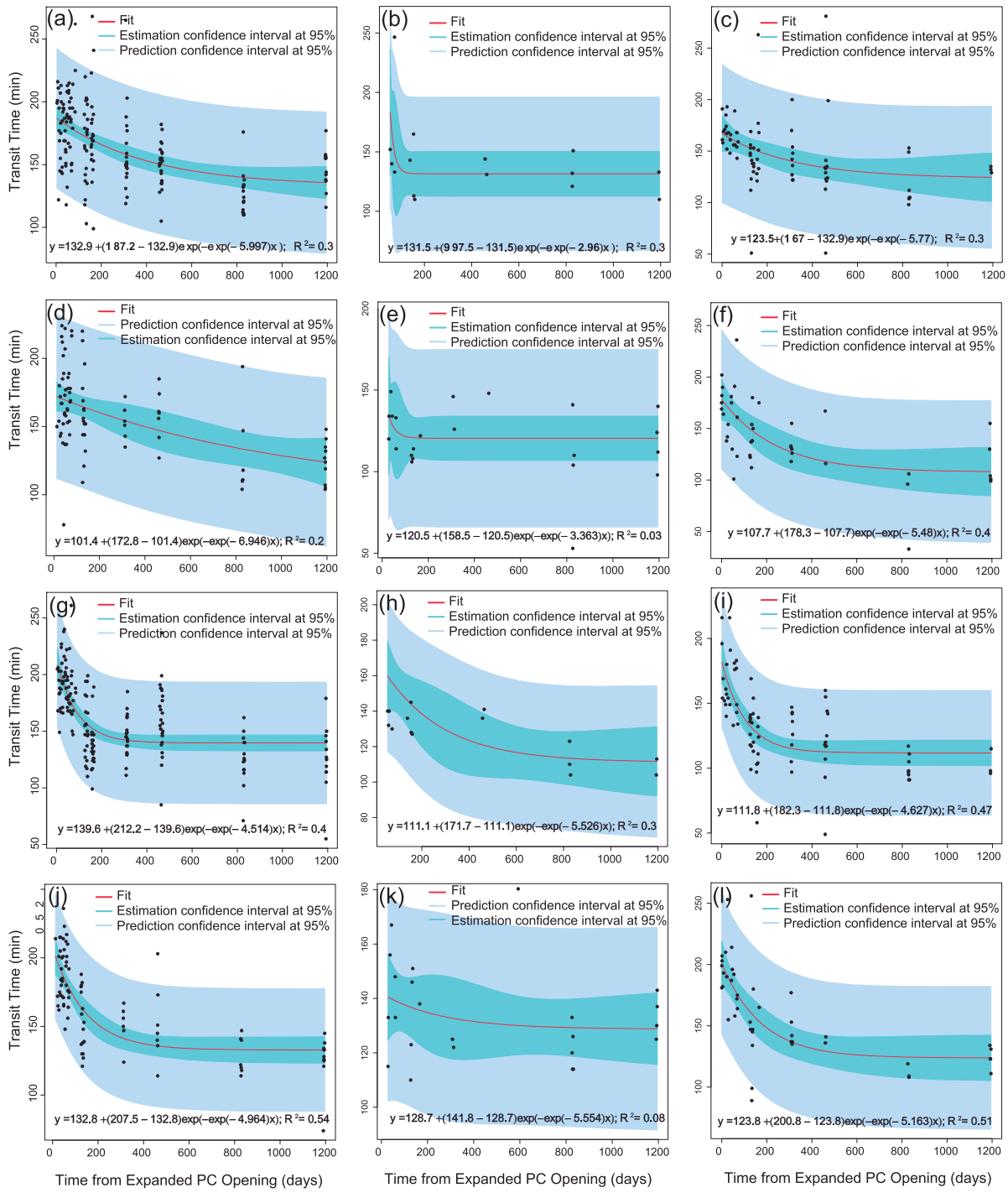

Figure 9. Scatterplots and the non-linear asymptotic fittings of time in transit depending on the time of experience of operating in the expanded Panama Canal. The first, second and third columns correspond to container, LNG and LPG vessels, respectively. The first, second, third and fourth rows account for the Cocoli lock - North direction, Cocoli lock - South direction, Agua Clara lock - North direction, and Agua Clara lock - South direction scenarios, respectively. In addition, the expression of the fitted non-linear asymptotic regression model and the determination coefficient are also included for each type of ship within each scenario.

of the fitted non-linear asymptotic regression model is included for each type of ship within each scenario.

Tables 7-10 show the estimates of the fitting models, including 95\% confidence intervals and tStudent $P$-values, for all the combinations of type of vessel, direction and lock. Assuming the $P$-values and confidence interval information, we cannot assume that the parameters $\left(R_{0}\right.$ and $\left.l r c\right)$ corresponding to the model fitted to LNG vessels are significantly different from zero when crossing the Cocolí lock. Therefore, we can infer that there is not a significant reduction in transit time when LNG vessels cross the Cocolí lock (see also Figure 9[b] and 9[e]). When the transits through Agua Clara lock are studied, 


\begin{tabular}{|c|c|c|c|c|c|c|c|c|c|}
\hline \multirow[b]{2}{*}{ Predictors } & \multicolumn{3}{|c|}{ Container vessels } & \multicolumn{3}{|c|}{ LNG vessels } & \multicolumn{3}{|c|}{ LPG vessels } \\
\hline & Estimates & CI & $P$-value & Estimates & CI & $P$-value & Estimates & $\mathrm{CI}$ & $P$-value \\
\hline Asym & $132 \cdot 90$ & 113.4 to $152 \cdot 4$ & $<0.001$ & $131 \cdot 46$ & $114 \cdot 3-148 \cdot 7$ & $<0.001$ & $123 \cdot 49$ & $94 \cdot 2$ to $152 \cdot 8$ & $<0.001$ \\
\hline$R_{0}$ & $187 \cdot 23$ & $178 \cdot 0$ to $196 \cdot 5$ & $<0.001$ & 997.45 & $-6958-8953$ & $0 \cdot 810$ & $166 \cdot 97$ & $149 \cdot 8$ to $184 \cdot 2$ & $<0.001$ \\
\hline $\operatorname{lrc}$ & $-6 \cdot 00$ & $-6 \cdot 89$ to $-5 \cdot 11$ & $<0.001$ & $-2 \cdot 96$ & $-6 \cdot 00-0 \cdot 08$ & $0 \cdot 081$ & -5.77 & -7.52 to -4.02 & $<0.001$ \\
\hline Observations & & 170 & & Observations & 15 & & Observations & 76 & \\
\hline$R^{2}$ & & $0 \cdot 26$ & & $R^{2}$ & 0.31 & & $R^{2}$ & $0 \cdot 15$ & \\
\hline
\end{tabular}

Note: The number of observations and the determination coefficient are also included. 
Table 8. Estimates of the asymptotic fitting model parameters with $95 \%$ confidence interval (CI) and the corresponding P-values using the t test for the Cocoli lock - South direction scenario.

\begin{tabular}{|c|c|c|c|c|c|c|c|c|c|}
\hline \multirow[b]{2}{*}{ Predictors } & \multicolumn{3}{|c|}{ Container ships } & \multicolumn{3}{|c|}{ LNG ships } & \multicolumn{3}{|c|}{ LPG ships } \\
\hline & Estimates & CI & $P$-value & Estimates & CI & $P$-value & Estimates & $\mathrm{CI}$ & $P$-value \\
\hline Asym & $101 \cdot 40$ & -29.40 to 232.20 & $0 \cdot 132$ & $120 \cdot 43$ & $107 \cdot 69-133 \cdot 18$ & $<\mathbf{0 . 0 0 1}$ & $107 \cdot 71$ & $83 \cdot 06$ to $132 \cdot 37$ & $<0.001$ \\
\hline$R_{0}$ & $172 \cdot 76$ & $161 \cdot 33$ to $184 \cdot 19$ & $<0.001$ & $158 \cdot 49$ & $-150 \cdot 05-467 \cdot 03$ & $0 \cdot 326$ & $178 \cdot 33$ & 158.86 to 197.81 & $<0.001$ \\
\hline $\operatorname{lrc}$ & $-6 \cdot 95$ & $-10 \cdot 05$ to -3.85 & $<0.001$ & $-3 \cdot 36$ & $-10 \cdot 06-3 \cdot 34$ & $0 \cdot 337$ & $-5 \cdot 48$ & -6.54 to -4.42 & $<0.001$ \\
\hline Observations & & 86 & & Observations & 23 & & Observations & 44 & \\
\hline$R^{2}$ & & $0 \cdot 2$ & & $R^{2}$ & 0.03 & & $R^{2}$ & $0 \cdot 4$ & \\
\hline
\end{tabular}

Note: The number of observations and the determination coefficient are also included. 


\begin{tabular}{|c|c|c|c|c|c|c|c|c|c|}
\hline \multirow[b]{2}{*}{ Predictors } & \multicolumn{3}{|c|}{ Container vessels } & \multicolumn{3}{|c|}{ LNG vessels } & \multicolumn{3}{|c|}{ LPG vessels } \\
\hline & Estimates & $\mathrm{CI}$ & $P$-value & Estimates & $\mathrm{CI}$ & $P$-value & Estimates & $\mathrm{CI}$ & $P$-value \\
\hline Asym & $139 \cdot 63$ & $132 \cdot 66$ to $146 \cdot 60$ & $<0.001$ & $111 \cdot 14$ & $90 \cdot 82$ to $131 \cdot 47$ & $<0.001$ & $111 \cdot 77$ & $102 \cdot 24$ to $121 \cdot 31$ & $<0.001$ \\
\hline$R_{0}$ & $212 \cdot 20$ & $196 \cdot 60$ to $227 \cdot 79$ & $<0.001$ & $171 \cdot 65$ & $135 \cdot 60$ to $207 \cdot 70$ & $<0.001$ & $182 \cdot 29$ & $165 \cdot 44$ to $199 \cdot 14$ & $<0.001$ \\
\hline $\operatorname{lrc}$ & $-4 \cdot 51$ & -4.97 to -4.05 & $<0.001$ & $-5 \cdot 53$ & $-7 \cdot 17$ to $-3 \cdot 88$ & $<0.001$ & $-4 \cdot 63$ & -5.19 to -4.07 & $<0.001$ \\
\hline $\begin{array}{l}\text { Observations } \\
R^{2}\end{array}$ & & 170 & & $\begin{array}{c}\text { Observations } \\
R^{2}\end{array}$ & $\begin{array}{c}15 \\
0.4\end{array}$ & & $\begin{array}{c}\text { Observations } \\
R^{2}\end{array}$ & $\begin{array}{c}75 \\
0.47\end{array}$ & \\
\hline
\end{tabular}

Note: The number of observations and the determination coefficient are also included. 
Table 10. Estimates of the asymptotic fitting model parameters with 95\% confidence interval (CI) and the corresponding P-values using the t test are shown for the Agua Clara lock - South direction scenario.

\begin{tabular}{|c|c|c|c|c|c|c|c|c|c|}
\hline \multirow[b]{2}{*}{ Predictors } & \multicolumn{3}{|c|}{ Container ships } & \multicolumn{3}{|c|}{ LNG ships } & \multicolumn{3}{|c|}{ LPG ships } \\
\hline & Estimates & $\mathrm{CI}$ & $P$-value & Estimates & $\mathrm{CI}$ & $P$-value & Estimates & CI & $P$-value \\
\hline Asym & $132 \cdot 80$ & $123 \cdot 29$ to $142 \cdot 31$ & $<0.001$ & $128 \cdot 72$ & 114.42 to 143.03 & $<0.001$ & $123 \cdot 76$ & $105 \cdot 48$ to $142 \cdot 03$ & $<0.001$ \\
\hline$R_{0}$ & $207 \cdot 48$ & $190 \cdot 24$ to $224 \cdot 72$ & $<0.001$ & $141 \cdot 85$ & 120.79 to 162.91 & $<0.001$ & $200 \cdot 76$ & 183.04 to 218.47 & $<0.001$ \\
\hline & $-4 \cdot 96$ & $-5 \cdot 56$ to $-4 \cdot 37$ & $<0.001$ & $-5 \cdot 55$ & -10.57 to -0.53 & $0 \cdot 042$ & $-5 \cdot 16$ & $-5 \cdot 93$ to $-4 \cdot 39$ & $<0.001$ \\
\hline Observations & & 86 & & Observations & 23 & & Observations & 44 & \\
\hline$R^{2}$ & & 0.54 & & $R^{2}$ & 0.08 & & $R^{2}$ & $0 \cdot 51$ & \\
\hline
\end{tabular}

Note: The number of observations and the determination coefficient are also included. 
the learning curve for LNG vessels is significant, as shown by Tables 9 and 10 but very weak, as shown by Figure 9(h) and 9(k). The transit of LNG vessels, due to their special cargo, is a priority with respect to other ships using the canal. In fact, at the beginning, the transit time of LNG vessels was much closer to the optimum than that of other vessels. Thus, the time taken for LNG vessels to pass through the locks has decreased slightly. On the other hand, more significant learning is observed for the container and LPG vessels. The relation between time in transit and experience time is closer to the asymptotic trend that accounts for the learning curve of operating the EPC. In fact, the fittings are closer to real data and the confidence bands are narrower (see Figure 9). The fitted model explains between 15\% and 54\% of the overall variability of the vessel transit times across the locks (see the $R^{2}$ values in Tables 7-10). Therefore, a very important part of the changes in transit time correspond to a decrease due to learning, in the specific case of container and LPG vessels, which account for the main part of the transits through the Panama Canal. The higher goodness of fit test is obtained for the transit time of LPG vessels, but it seems that the effect of learning is similar in the two types of vessels. Indeed, if we calculate the difference between R0 and Asym parameters, the improvement of the LPG vessels in these three years is 77 min (Agua Clara - South), 70.52 min (Agua Clara - North), 70.62 min (Cocolí - South), and $43.48 \mathrm{~min}$ (Cocolí - North), whereas in the case of container vessels it is $74.68 \mathrm{~min}$ (Agua Clara South), 72.57 min (Agua Clara - North), 71.36 min (Cocolí - South), and 54.33 min (Cocolí - North). At this regard, it is important to note that the combination of Agua Clara - South is the scenario where the highest value of learning is attained, which corresponds to the entry of ships from the Atlantic.

The latter results show that, in general terms, it seems that the effect of learning on transit time is more significant and important in magnitude in Agua Clara lock than in Cocolí lock. The panels of Figure 9 show that the fittings corresponding to the Agua Clara lock (Figure 9[g]-9[1]) are closer to the real data (see trends, width of the intervals and $R^{2}$ coefficient). In addition, if the estimates for the lrc parameter are observed, the rate of change of transit time is higher in Agua Clara lock (higher values of lrc correspond to higher rate of change). In other words, the learning is more rapid in Agua Clara lock.

When comparing the learning curves for Agua Clara lock with respect to the learning curve of the pilot training in the Baroque vessel, we observe that the explained variance of the fitted asymptotic model is similar, about 50\%, although the rate of learning is less for the actual operation (in terms of lrc parameter). Moreover, the lowest expected times in transit in 2019 were about $101 \mathrm{~min}$ in Cocolí lock and about $112 \mathrm{~min}$ in Agua Clara lock, rather lower than the final time reached of 179 min corresponding to the training in the Baroque vessel.

Taking into account the results shown in Tables 7-10 and Figure 9, it seems that the time in transit through the locks of the EPC has been optimised with the current resources in terms of manpower, installations, technology and logistics. It is interesting to note that now there is greater room for improvement for the transit through Cocolí lock than Agua Clara lock. Further improvements could involve changes in at least some of the abovementioned resources.

\section{Conclusions}

The time in transit through the locks of the EPC as a function of time of experience, the EPC learning curve, has been modelled by fitting non-linear asymptotic regression models. The exploratory analysis and the results of the application of GAM modelling support this procedure. This means that at the beginning there was wide room for improvement and all the actions performed by the APC led to large decreases in transit time, but the rate of change continuously decreased until reaching an asymptote. Further improvements could involve changes in at least some of resources, such as manpower, installations, technology, and logistics.

Apart from the learning effect, we have found that the transit time through locks significantly depends on type of vessel, transit direction and lock. In fact, the expected transit time takes longer for the Agua Clara lock, South direction and container vessels. Thus, a different asymptotic non-linear model has been fitted for each combination of levels of the three mentioned factors. 
The asymptotic non-linear regression model has been fitted in 12 different scenarios, explaining between $15 \%$ and $54 \%$ of the overall variability of the vessel transit times through the locks. These fittings are estimates of the learning curves of operating the EPC, and, as just mentioned, account for $15 \%-54 \%$ of the overall variability of the transit time.

The special traffic conditions of LNG vessels (they have priority in the traffic due to their cargo) prevent, to a great extent, observation of the effect of the training and the experience on the transit time. In fact, only in the Agua Clara lock was a significant asymptotic decrease of vessel time in transit through the lock with respect to time observed. The effect of the time of experience is rather higher in container and LPG vessels.

Considering the fitted parameters of the asymptotic non-linear regression model, the decrease in transit time through the locks for LPG vessels over three years is $77 \mathrm{~min}$ (Agua Clara - South), $70.52 \mathrm{~min}$ (Agua Clara - North), 70.62 min (Cocolí - South), and $43.48 \mathrm{~min}$ (Cocolí - North), whereas in the case of container vessels it is $74.68 \mathrm{~min}$ (Agua Clara - South), $72.57 \mathrm{~min}$ (Agua Clara - North), $71.36 \mathrm{~min}$ (Cocolí - South), and 54.33 min (Cocolí - North). The combination Agua Clara lock and South direction, which corresponds to the entry of ships from the Atlantic, is the scenario where the greatest learning was attained.

The effect of learning on transit time is higher in magnitude and in terms of rate of learning in Agua Clara lock than in Cocolí lock, taking into account the parameters of the fittings. In addition, the learning curves are closer to the asymptotic model. In other words, the learning tends to be greater and more rapid in Agua Clara lock.

Acknowledgment. The research of Salvador Naya and Javier Tarrío has been supported by MINECO grant MTM2017-82724-R, and by the Xunta de Galicia (Grupos de Referencia Competitiva ED431C-2020-14 and Centro de Investigación del Sistema universitario de Galicia ED431G 2019/01), all of them through the ERDF. This work has been funded in part by Project 1-FACINA of the International Maritime University of Panama (UMIP).

\section{References}

Argote, L. and Epple, D. (1990). Learning curves in manufacturing. Science, 247(4945), 920-924.

ACP. (2006a). Plan Maestro 2005-25. Autoridad del Canal de Panamá. Available at: www.pancanal.com [Accessed Jul. 2019].

ACP. (2006b). Proposal for the Expansion of the Panama Canal. Third Set of Locks Project. Autoridad del Canal de Panamá. 24 April 2006, pp. 34-38.

Baloff, N. (1971). Extension of the learning curve-some empirical results. Journal of the Operational Research Society, 22(4), 329-340.

Bates, D. M. and Watts, D. G. (2007). Nonlinear Regression Analysis and its Applications. New York: Wiley.

Box, G. E. P. (2011). Graphical analysis of variance. In: Lovric, M. (ed.). International Encyclopedia of Statistical Science, Berlin and Heidelberg: Springer, 614-618.

Carral, L., Tarrío-Saavedra, J., Naya, S., Bogle, J. and Sabonge, R. (2017). Effect of inaugurating the third set of locks in the Panama Canal on vessel size, manoeuvring and lockage time. Journal of Navigation, 70(6), 1205-1223.

Carral, L., Tarrio-Saavedra, J., Castro-Santos, L., Lamas-Galdo, I. and Sabonge, R. (2018a). Effects of the expanded Panama Canal on vessel size and seaborne transport. Promet-Traffic \& Transportation, 30(2), 241-251.

Carral, L., Tarrio-Saavedra, J., Crespo-Pereira, D., Fernandez-Campoamor, M. and Sabonge, R. (2018b). Analysis of the competitive position of the expanded Panama Canal in the shipment of LNG between the Atlantic and Pacific. Proceedings of the Institution of Mechanical Engineers, Part M: Journal of Engineering for the Maritime Environment. doi:10.1177/1475090218812242

Carral, L., Tarrio-Saavedra, J., Alvarez-Feal, C., Naya, S. and Sabonge, R. (2019a). Statistical methodology to determine the transit time required for Neopanamax vessels in the Panama Canal. Journal of Marine Science and Technology. doi:10.1007/s00773-019-00650-3

Carral, L., Fernández-Garrido, C., Vega, A. and Sabonge, R. (2019b). Importance of the Panama Canal in the reduction of CO2 emissions from maritime transport. International Journal of Sustainable Transportation. doi:10.1080/15568318.2019. 1632994

Carral, L., Tarrio-Saavedra, J., Rodriguez, A. and Naya, S. (2020). Modeling the Learning Curve Corresponding to the Transit Through the New Expanded Panama Canal. Approved in Proceedings of the 26th Pan-American Conference of Naval Engineering - COPINAVAL. Springer International Publishing.

Chung, S. (2001). The learning curve and the yield factor: The case of Korea's semiconductor industry. Applied Economics, 33(4), 473-483.

Conley, P. (1970). Experience curves as a planning tool. IEEE Spectrum, 7(6), 63-68. 
Cook, J. E. (1991). A competitive model of the Japanese firm. Journal of Policy Modeling, 13(1), 93-114.

Dorroh, J. R., Gulledge, T. R. and Womer, N. K. A. (1986). Generalization of the learning curve. European Journal of Operational Research, 26, 205-216.

Economic Commission for Europe (1965). Effect of Repetition on Building Operations and Processes on Site: Report of an Enquiry Undertaken by the Committee on Housing, Building and Planning. New York, United Nations. Available at: http:// books.google.com.lb/books?id $\{\backslash$ mathsurround=lopskip\$=\$ 5 cV8QgAACAAJ [Accessed 5 Nov. 2015].

Gottlieb, S. C. and Haugbølle, K. (2010). The Repetition Effect in Building and Construction Works: A Literature Review. Aalborg, Denmark: Danish Building Research Institute, Aalborg University.

Grothendieck, G. (2013). nls2: Non-Linear Regression with Brute Force. R package version 0.2. Available at: https://CRAN.Rproject.org/package $\{$ \mathsurround=lopskip $\$=\$$ nls2

Gruber, H. (1992). The learning curve in the production of semiconductor memory chips. Applied Economics, 24(8), 885-894.

Gruber, H. (1994). The yield factor and the learning curve in semiconductor production. Applied Economics, 26(8), 837-843.

Gruber, H. (1996). Trade policy and learning by doing: The case of semiconductors. Research Policy, 25(5), 723-739.

Gruber, H. (1998). Learning by doing and spillovers: Further evidence for the semiconductor industry. Review of Industrial Organization, 13(6), 697-711.

Hamade, R. F., Jaber, M. Y. and Sikström, S. (2009). Analyzing CAD competence with univariate and multivariate learning curve models. Computers \& Industrial Engineering, 56(4), 1510-1518.

Henderson, B. D. (1973). The Experience Curve-Reviewed. IV. The Growth Share Matrix of the Product Portfolio. Boston Consulting Group. Available at: https://www.bcg.com/documents/file13904.pdf [Accessed Dec. 2019].

Hinze, J. and Olbina, S. (2009). Empirical analysis of the learning curve principle in prestressed concrete piles. Journal of Construction Engineering and Management, 425-431. doi: 10.1061/(ASCE)CO.1943-7862.0000004

Hughes, C. (2009). When is a VTS not a VTS? Journal of Navigation, 62(3), 439-442. doi:10.1017/S0373463309005396

Jaber, M. Y. and Guiffrida, A. L. (2004). Learning curves for processes generating defects requiring reworks. European Journal of Operational Research, 159(3), 663-672.

Janeiro-Arocas, J., Tarrío-Saavedra, J., López-Beceiro, J., Naya, S., López-Canosa, A. and Heredia-García, N. (2016). Creep analysis of silicone for podiatry applications. Journal of the Mechanical Behavior of Biomedical Materials, 63, $456-469$.

Jarkas, A. M. (2010). Critical investigation into the applicability of the learning curve theory to rebar fixing labor productivity. Journal of Construction Engineering and Management, 1279-1288. doi:10.1061/(ASCE)CO.1943-7862.0000236

Jarkas, A. and Horner, M. (2011). Revisiting the applicability of learning curve theory to formwork labour productivity. Construction Management and Economics, 29(5), 483-493.

Jordan Srour, F., Kiomjian, D. and Srour, I. M. (2016). Learning curves in construction: a critical review and new model. Journal of Construction Engineering and Management, 142(4), 06015004.

Lam, K. C., Lee, D. and Hu, T. (2001). Understanding the effect of the learning-forgetting phenomenon to duration of projects construction. International Journal of Project Management, 19(7), 411-420.

Lefcovich, M. (2003). Kaizen - La mejora continua y el cuadro de mando integral. Available at: http://studylib.es/doc/493795/t $\%$ C3\% ADtulo--kaizen- \% E2\% $80 \% 93$-la-mejora-continua-y-la-curva-de

Lieberman, M. B. (1984). The learning curve and pricing in the chemical processing industries. RAND Journal of Economics 15(2), 213-228.

Maechler, M., Rousseeuw, P., Croux, C., Todorov, V., Ruckstuhl, A., Salibian-Barrera, M., Verbeke, T., Koller, M., Conceicao, E. and di Palma, M. A. (2019). robustbase: Basic Robust Statistics R package version 0.93-5. Available at: http:// CRAN.R-project.org/package $\{$ mathsurround=lopskip $\$=\$$ \}robustbase

Malyusz, L. and Pem, A. (2014). Predicting future performance by learning curves. Procedia Social Behavioral Sciences, 119, 368-376.

McCullough, D. (1977). The Path Between the Seas: The Creation of the Panama Canal 1870-1914. New York: Simon \& Schuster (Classic edition, 2019).

Mosheiov, G. and Sidney, J. B. (2003). Scheduling with general job-dependent learning curves. European Journal of Operational Research, 147, 665-670.

Mullen, K., Ardia, D., Gil, D., Windover, D. and Cline, J. (2011). 'Deoptim': an R package for global optimization by differential evolution. Journal of Statistical Software, 40(6), 1-26.

Nemet, G. F. (2006). Beyond the learning curve: factors influencing cost reductions in photovoltaics. Energy Policy, 34(17), 3218-3232.

Panas, A. and Pantouvakis, J. P. (2014). Simulation-based and statistical analysis of the learning effect in floating caisson construction operations. Journal of Construction Engineering and Management. doi:10.1061/(ASCE)CO.1943-7862 .0000782. 04013033 .

Pinheiro, J. and Bates, D. (2000). Mixed-Effects Models in S and S-PLUS Statistics and Computing. New York: Springer.

Pinheiro, J., Bates, D., DebRoy, S. and Sarkar, D. (2018). R Core Team. nlme: Linear and Nonlinear Mixed Effects Models. Available at: https://CRAN.R-project.org/package $\{\backslash$ mathsurround=lopskip $\$=\$\}$ nlme.

Ríos-Fachal, M., Tarrío-Saavedra, J., López-Beceiro, J., Naya, S. and Artiaga, R. (2014). Optimizing fitting parameters in thermogravimetry. Journal of Thermal Analysis and Calorimetry, 116(3), 1141-1151.

Robles-Bykbaev, Y., Tarrio-Saavedra, J., Quintana-Pita, S., Diaz-Prado, S., Saban, F. J. G. and Naya, S. (2018). Statistical degradation modelling of poly (D, L-lactide-co-glycolide) copolymers for bioscaffold applications. PloS One, 13(10), e0204004. 
Rodriguez, M. (2011). El esquema de practicaje en el canal de panama. monografía—seminario internacional: Canal de panamá: El reto de la ampliación de la vía interoceánica o cómo diseñar, construir y gestionar una de las obras de ingeniería más grandes del mundo. Available at: https://www.fundacionareces.tv/watch/canalde_panama? as $\{$ mathsurround=lopskip\$=\$4f0ca68694a05fc458070000 [Accessed May 2019].

Tarrío-Saavedra, J., González, C. G., Naya, S., López-Beceiro, J. and Ponton, A. (2017). Statistical modeling applied to deformation-relaxation processes in a composite biopolymer network induced by magnetic field. PloS One, 12(1), e0169866.

Thomas, H. R. (2009). Construction learning curves. Practice Periodical on Structural Design and Construction, 14-20. doi:10.1061/(ASCE)1084-0680(2009)14:1(14).

Thomas, H. R., Mathews, C. T. and Ward, J. G. (1986). Learning curve models of construction productivity. Journal of Construction Engineering and Management, 245-258. doi:10.1061/(ASCE)0733-9364(1986)112:2(245).

Ulusçu, Ö., Özbaş, B., Altıok, T., Or, İ. and Yılmaz, T. (2009). Transit vessel scheduling in the Strait of Istanbul. Journal of Navigation, 62(1), 59-77. doi:10.1017/S0373463308005092

Wong, P. S., On Cheung, S. and Hardcastle, C. (2007). Embodying learning effect in performance prediction. Journal of Construction Engineering and Management, 474-482. doi:10.1061/(ASCE)0733-9364(2007)133:6(474)

Wood, S. N. (2017). Generalized Additive Models: An Introduction With R. CRC Press.

Wright, T. P. (1936). Learning curve. Journal of Aeronautical Sciences, 3(4), 122-128.

Yelle, L. E. (1980). Industrial life cycles and learning curves: Interaction of marketing and production. Industrial Marketing Management, 9(4), 311-318.

Zhang, L., Zou, X. and Kan, Z. (2014). Improved strategy for resource allocation in repetitive projects considering the learning effect. Journal of Construction Engineering and Management, 04014053. doi:10.1061/(ASCE)CO.1943-7862.0000896

Cite this article: Carral L, Tarrío-Saavedra J, Sáenz AV, Bogle J, Alemán G, Naya S (2021). Modelling operative and routine learning curves in manoeuvres in locks and in transit in the expanded Panama Canal. The Journal of Navigation 74: 3, 633-655. https://oi.org/10.1017/ S0373463320000727 